Volume 70: Part 2

\title{
THE ROYAL SOCIETY OF EDINBURGH
}

\section{PROCEEDINGS}

Section B (Biology)

PUBLISHED BY THE ROYAL SOCIETY OF EDINBURGH 22 GEORGE STREET, EDINBURGH 2 Price: 35 s. $\$ 6.00$ 


\section{ROYAL SOGIETY OF EDINBURGH}

\section{2, 24 GEORGE STREET, EDINBURGH, 2}

\section{NOTES ON THE PREPARATION OF PAPERS FOR THE TRANSACTIONS AND PROCEEDINGS OF THE SOCIETY}

A PAPER by a non-Fellow must be communicated by a Fellow or Honorary Fellow of the Society. The communicator should satisfy himself that the paper is suitable for presentation to the Society.

A paper by more than one author must be submitted with a statement, signed by each author, to the effect that the paper in its entirety is approved by the joint authors, and naming the author who will be responsible for the correction of proofs.

In view of the high cost of publication, authors must write their papers as concisely as possible, and avoid excess of illustrations. The MS. must be easily legible, preferably typewritten on one side of quarto or foolscap paper, and with pages numbered throughout. It must be in its final form for printing. Authors are advised to retain copies of their papers as the Society cannot accept responsibility for safe custody.

Every paper must be accompanied by a synopsis, in general not exceeding 200 words, which will be printed in small type at the beginning of the paper, immediately after the title. The synopsis will not necessarily replace a "Summary of Conclusions" which, if required, will be printed in ordinary type at the end of the paper.

In the case of a long paper a table of contents should be supplied. References to plates, etc. should be inserted in the MS. where required. Positions for the insertion of illustrations appearing in the text should be indicated. Names of genera and species should be in italics. Footnotes should be avoided where possible.

Additions to a paper after it has been finally passed for printing will, if accepted by the Council, be treated and dated as separate communications, and may, or may not, be printed immediately after the original paper.

References to Literature cited in the text should be listed at the end of a paper. They should be arranged alphabetically under the authors' names, with titles of journals abridged as given in the World List of Scientific Periodicals, except that in periodicals with English titles the ordinary English use of capital letters should be followed, e.g. Proc. Linn. Soc. Titles of papers, if inserted, should be quoted exactly. The undernoted are examples:

Artren, A. C., 1946. "On the estimation of many statistical parameters", Proc. Roy. Soc, Edinb., A, 63, 369-377.

GUTHRIE, D., 1945. A History of Medicine. London.

Rogres, G. L., 1952. Proc. Roy. Soc. Edinb., A, 63. 193-221.

References in the text should be made by quoting the name of the author and year of publication, thus: (Rogers 1952) or (Guthrie 1945), adding the page when necessary. When two or more papers, published by the same author in any one year, are listed, each paper should be distinguished by a small letter $a, b$, etc. placed after the date, thus: (Rogers I952 $a$ ). All references should be carefully checked before the paper is submitted.

Illustrations. These should preferably be line drawings (shaded by dotting, hatching, etc. if necessary). Alternatively wash drawings or photographs, which are usually reproduced as plates, may be accepted. All illustrations must be in a form suitable for reproduction.

Line drawings should be made with Indian ink on white Bristol board. Lines or dots, etc., used for shading, should be firm and black and no washes or colour should be used. Areas where lines, stipples, etc. are to be added by the engraver should be marked lightly in blue pencil, and the type of shading indicated.

Wash drawings should be shaded in monochrome (black or sepia), and drawn on white paper or white Bristol board.

All drawings should, where possible, allow of reduction to about two-thirds the linear dimensions, and the amount of the reduction should be considered, during drafting, with regard to the size and strength of shading, lettering, lines, etc. Drawings should be submitted, if possible, flat, not rolled. 